\title{
Modelling and assessment of business cases for smart multi-energy districts
}

\section{Document Version}

Accepted author manuscript

Link to publication record in Manchester Research Explorer

\section{Citation for published version (APA):}

Good, N., \& Mancarella, P. (2016). Modelling and assessment of business cases for smart multi-energy districts. In Power Systems Computation Conference (PSCC), 2016

\section{Published in:}

Power Systems Computation Conference (PSCC), 2016

\section{Citing this paper}

Please note that where the full-text provided on Manchester Research Explorer is the Author Accepted Manuscript or Proof version this may differ from the final Published version. If citing, it is advised that you check and use the publisher's definitive version.

\section{General rights}

Copyright and moral rights for the publications made accessible in the Research Explorer are retained by the authors and/or other copyright owners and it is a condition of accessing publications that users recognise and abide by the legal requirements associated with these rights.

\section{Takedown policy}

If you believe that this document breaches copyright please refer to the University of Manchester's Takedown Procedures [http://man.ac.uk/04Y6Bo] or contact uml.scholarlycommunications@manchester.ac.uk providing relevant details, so we can investigate your claim.

\section{OPEN ACCESS}




\title{
Modelling and assessment of business cases for smart multi-energy districts
}

\author{
Nicholas Good, Pierluigi Mancarella \\ Electrical Energy and Power Systems Group, School of Electrical and Electronic Engineering \\ University of Manchester \\ Manchester, UK \\ \{nicholas.good,p.mancarella\}@manchester.ac.uk
}

\begin{abstract}
This work presents a stochastic mixed integer linear program based model, for optimization and business case assessment of smart multi-energy districts (including electricity, heat and gas). The model is general and extensible, and can include multiple types of multi-energy generation and consumption. In particular, it is capable of co-optimization of energy and capacity, for participation in multiple energy/reserve/capacity markets. Further, the model incorporates a level-of-aggregation approach, which facilitates modelling and assessment of physical and virtual aggregation within districts. The model is demonstrated through application to a case study district in the Irish energy system. Prices from the various relevant energy markets and charging regimes are presented, before the results of optimization with respect to various business cases are explored. The value of optimization on retail prices, various energy/capacity-related markets/charging regimes, and of aggregation is demonstrated. Directions for further application of the model are detailed.
\end{abstract}

Index Terms-Aggregation, business case, multi-energy, smart districts, stochastic optimization

\section{ACRONYMS}

BC Business Case

BSUoS Balancing Services Use-of-System

CHP Combined Heat and Power

CP Capacity Payments

DA Day-Ahead

DA\&I Day-Ahead \& Imbalance

DC District Coordination

DPW District Private Wire

DR Demand Response

EB Electric Boiler

EDUoS Electricity Distribution Use-of-System

ETUoS Electricity Transmission Use-of-System

EHP Electric Heat Pump

GCP Grid Connection Point

ICT Information and Computation Technology

ISP Imbalance Settlement Process

OR Operating Reserve

RO Retail Optimization

TES Thermal Energy Store

\begin{abstract}
UoS Use-of-System
VAT Value-Added-Tax

VPP Virtual Power Plant

WT Wind Turbine
\end{abstract}

NOTATION

Indices

$g \quad$ index of grid connection points, 1 to $N_{g}$

$i \quad$ index of settlement periods, 1 to $N_{i}$

$l \quad$ index of locations, 1 to $N_{l}$

$S \quad$ index of scenarios, 1 to $N_{s}$

$v \quad$ index of VPPs, 1 to $N_{v}$

Maps

$\Phi_{g, l}^{G L} \quad$ map of GCP to location

$\Phi_{v, g}^{V G} \quad$ map of VPP to GCP

Parameters

Resource

$C x_{l} \quad$ thermal capacitance of TES $\left(\mathrm{kWh} /{ }^{\circ} \mathrm{C}\right)$

$P(t)_{l}^{\text {CHPmin }} \quad$ CHP minimum heating power $(\mathrm{kW})$

$P(t)_{l}^{C H P \max } \quad$ CHP maximum heating power $(\mathrm{kW})$

$P(t)_{l}^{E B \min } \quad$ electric boiler min heating power $(\mathrm{kW})$

$P(t)_{l}^{E B \max } \quad$ electric boiler max heating power $(\mathrm{kW})$

$P(t)_{l}^{G B \min } \quad$ gas boiler minimum heating power $(\mathrm{kW})$

$P(t)_{l}^{G B \max } \quad$ gas boiler maximum heating power $(\mathrm{kW})$

$\eta_{l}^{e} / \eta_{l}^{t} \quad$ CHP unit electrical/thermal efficiency (-)

$\eta_{l}^{G B} / \rho_{l}^{E B} \quad$ gas/electric boiler efficiency (-)

$\rho_{s, i, l}^{E H P} \quad$ EHP coefficient of performance (-)

$P(e)_{l}^{\text {EHPmin }} \quad$ EHP minimum electrical power $(\mathrm{kW})$

$P(e)_{l}^{E H P \max } \quad$ EHP maximum electrical power $(\mathrm{kW})$

$R x_{l} \quad$ thermal resistance of TES $\left({ }^{\circ} \mathrm{C} / \mathrm{kW}\right)$

$X_{l}^{\min } / X_{l}^{\max } \quad \min / \max$ temperature of TES $\left({ }^{\circ} \mathrm{C}\right)$

Consumer Energy/Occupancy Scenario Profiles

$L_{s, i, l}^{D H W} \quad$ domestic hot water load (kWh)

$L_{s, i, l}^{S H} \quad$ space heating load (kWh)

$E_{s, i, l}^{l o a d} \quad$ non-heating (base) electricity load (kWh)

Price/Weather Profiles and Parameters

$\lambda_{i} \quad$ day-ahead electricity price $(£ / \mathrm{kWh})$ 


\begin{tabular}{|c|c|}
\hline$\mu_{s, i}^{-}$ & imbalance electricity import price $(£ / \mathrm{kWh})$ \\
\hline$\mu_{s, i}^{+}$ & imbalance electricity export price $(\mathfrak{f} / \mathrm{kWh})$ \\
\hline$\gamma_{i}$ & gas price $(\mathfrak{£} / \mathrm{kWh})$ \\
\hline$\pi_{i}^{d} / \pi_{i}^{u}$ & down/up-reserve availability price $(\mathfrak{f} / \mathrm{kW})$ \\
\hline$\chi(g)_{s, i, g}^{-}$ & GCP electricity import price $(£ / k W h)$ \\
\hline$\varepsilon(g)_{s, i, g}^{-}$ & GCP gas import price $(£ / k W h)$ \\
\hline$\chi(l)_{l}^{-}$ & location electricity import price $(\mathfrak{f} / \mathrm{kWh})$ \\
\hline$\varepsilon(l)_{l}^{-}$ & location gas import price $(£ / k W h)$ \\
\hline $\mathcal{X}_{l}^{C H P}$ & CHP incentive $\left(£ / \mathrm{kWh}_{\text {CHPelectricity }}\right)$ \\
\hline $\mathcal{H}_{l}^{P V}$ & photo-voltaic incentive $(\mathfrak{f} / \mathrm{kWh}$ PVelectricity $)$ \\
\hline $\mathcal{H}_{l}^{W T}$ & WT incentive $\left(£ / k W h_{W T e l e c t r i c i t y ~}\right)$ \\
\hline $\mathcal{\varkappa}_{l}^{E H P}$ & EHP incentive ( $\left(\right.$ /kWh $\left.h_{\text {EHPheat }}\right)$ \\
\hline$E_{s, i, l}^{\text {solar }}$ & solar electricity generation (kWh) \\
\hline$E_{s, i, l}^{\text {wind }}$ & $\begin{array}{l}\text { wind electricity generation }(\mathrm{kWh}) p_{S} \\
\text { scenario probability }(-)\end{array}$ \\
\hline \multicolumn{2}{|c|}{ Time-band Length } \\
\hline$t$ & length of time step (h) \\
\hline \multicolumn{2}{|l|}{ Variables } \\
\hline$H_{s, i, l}^{\text {in }} / H_{s, i, l}^{\text {out }}$ & heat in/out to TES (kWh) \\
\hline$H_{s, i, l}^{C H P} / H_{s, i, l}^{E H}$ & heat from CHP/EHP $(\mathrm{kWh})$ \\
\hline$H_{s, i, l}^{E B} / H_{s, i, l}^{G B}$ & heat from $\mathrm{EB} /$ gas boiler $(\mathrm{kWh})$ \\
\hline$M_{i, v}$ & day-ahead energy import (kWh) \\
\hline$I_{s, i, v}^{-} / I_{s, i, v}^{+}$ & imbalance energy import/export (kWh) \\
\hline$G(v)_{s, i, v}^{-}$ & gas import, VPP level (kWh) \\
\hline$R_{i, l}^{r e s d} / R_{i, l}^{r e s u}$ & down/up-reserve location level $(\mathrm{kW})$ \\
\hline$R_{v}^{\text {resvd } / R_{v}^{\text {resvu }}}$ & down/up-reserve, VPP level $(\mathrm{kW})$ \\
\hline$z_{s, i, g}$ & GCP level import/export binary variable \\
\hline$E(g)_{s, i, g}^{-}$ & electricity import, GCP level (kWh) \\
\hline$G(g)_{s, i, g}^{-}$ & gas import, GCP level (kWh) \\
\hline$y_{s, i, l}$ & location level import/export binary variable \\
\hline$E(l)_{s, i, l}^{-}$ & electricity import, location level (kWh) \\
\hline$G(l)_{s, i, l}^{-}$ & gas import, location level (kWh) \\
\hline$X_{s, i, l}$ & energy level of thermal energy store $(\mathrm{kWh})$ \\
\hline$T_{s, i, l}^{T E S e n v}$ & TES environment temperature $\left({ }^{\circ} \mathrm{C}\right)$ \\
\hline
\end{tabular}

In recent years, concerns on energy affordability, security and sustainability (the 'energy trilemma') have combined to motivate a shift away from 'traditional' energy systems, to more liberalized, decentralized and interconnected ones. In the traditional energy system, large, centralized (and often high-carbon) electricity generators supplied electricity to passive consumers. This was facilitated by electricity networks with substantial redundancy, designed to deal with one-way electricity flows. Supply of gas, where present, followed similar principles, with little interconnection between the two energy vectors. Spurred by the above described 'energy trilemma', information and computation technology (ICT) advances [1], [2], and liberalization of the energy sector [3], this paradigm is being challenged. Increasingly, new (or currently niche) technologies are being deployed to generate electricity closer to consumption, to generate electricity and heat less carbon intensively, and/or to reduce reliance on energy grids.
Central to this new paradigm is the idea of flexibility. Increased energy system flexibility (together with strategic grid enhancement) have been identified as an essential enabler to this paradigm shift [4]. Flexibility is required (or desirable, given the cost of alternatives) to integrate new technologies on both the supply- and demand-side. It is required to integrate increasing amounts of non-dispatchable, variable renewable generation, to avoid costly transmission and distribution grid enhancements, and unnecessary back-up generation. It is also required to integrate increasing amounts of electric vehicles and electric heaters (which may, themselves, be sources of flexibility), to avoid expansion of the distribution network, and to cater for increased peak loads.

Flexibility can be provided in many ways, one of which is demand response (DR). All demand-side entities have the potential to engage in DR. However, districts, which are suitably enabled by 'smart' (ICT) technologies, and have the requisite storage and multi-energy infrastructure, may be especially well placed thanks to their combination of user types (increasing diversity in demand for energy services), and mix of consumption and (distributed) generation [5].

Effective exploitation of the DR available from such smart, multi-energy districts requires not only the necessary infrastructure, but also (in a liberalized energy system) the business case (BC) (i.e., the logic and quantitative assessment of an intervention), to link owners of flexibility to buyers. Assessment of such BCs requires stochastic, physically based models of the district, which are able to value both energy, and capacity (for reserve or capacity markets).

There are several examples in the existing literature of assessment of BCs for demand-side interventions. Assessed interventions include physical interventions, such as insulation improvement [6], solar photo-voltaic panels [7], combined heat and power (CHP) units [8] and private electricity and heat networks [9], [10]. Additionally commercial interventions, i.e., virtual aggregation of resources, have been considered [11]. However, the focus of the highlighted works on individual interventions means that there is a gap for a more general approach, able to incorporate any of the interventions that can be considered in a district. This is particularly important for capture of dependencies between energy vectors, e.g., electro-thermal device reserve dependent on heat demand. Further, existing work tends to not consider price signals from the various markets and charging regimes which constitute energy-related prices. Finally, although there are works which cover energy and reserve/capacity co-optimization [12], there are none which incorporate such a model into a district $\mathrm{BC}$ assessment.

Considering the problem formulation, comparison may be drawn to tools for self-scheduling of virtual power plants (VPPs), or similar entities. Here there are also gaps to be found, as those works which do consider multi-energy optimization, [13]-[15], do not consider reserves from electro-thermal devices.

Given the identified gaps in the literature, this work proposes a two-stage (day-ahead - DA - and real-time) stochastic energy/capacity co-optimization model, building on the 
energy optimization model proposed in [16]. This model may be employed as a self-scheduling tool for an aggregator (or similar party) with the responsibility to optimize a smart district, or it may be used by any interested party to understand the value of various business cases for one or more districts (or VPPs). The proposed model can interact with electricity and gas grids, and includes thermal storage, and multiple types of electrical/heat generators. District modelling is enabled through utilization of the aggregation modelling approach introduced in [17]. Specifically, in addition to previous work [16], this work incorporates modelling of reserve from electro-thermal technologies, whilst, in addition to [17] the application of the aggregation modelling approach in an optimization model formulation is demonstrated.

In the remainder of this paper, the stochastic energy/capacity optimization model is detailed in Section II. Subsequently, a case study (a district in the Irish system) is described in Section III, before the associated results are presented in Section IV. Finally, conclusions are presented in Section V.

\section{PROBLEM FORMULATION}

The district energy resources are modelled using a mixed integer linear programming model. Thermal/electro-thermal generators and storage are modelled for each location. This includes modelling of the reserve capability of each flexible electricity generating/consuming device. Subsequently, energy balances at the location, grid connection point (GCP) and commercial (VPP) level are modelled. These separate balances enable the modelling of physical and virtual aggregation, as may be relevant in district applications [17]. Finally, the objective function, with various energy/capacity price components, is detailed.

\section{A. Modelling the resource}

\section{1) Heating plant and storage operating limits}

Constraints (1)-(4) set the operational limits of the various heating technologies. Electric heat pump (EHP) limits are defined by the electrical power limits of the EHP, as heat output limits of an EHP will vary materially as the EHP source temperature (and hence coefficient of performance) varies.

$$
\begin{aligned}
& P(t)_{l}^{G B m i n} t \leq H_{s, i, 1}^{G B} \leq P(t)_{l}^{G B m a x} t \\
& P(t)_{l}^{C H P \min } t \leq H_{s, i, 1}^{C H P} \leq P(t)_{l}^{C H P \max } t \\
& P(e)_{l}^{E H P m i n} \rho_{s, i, l}^{E H P} t \leq H_{s, i, l}^{E H P} \leq P(e)_{l}^{E H P m a x} \rho_{s, i, l}^{E H P} t \\
& P(t)_{l}^{E B \min ^{2}} t \leq H_{s, i, 1}^{E B} \leq P(t)_{l}^{E B m a x} t
\end{aligned}
$$

For all $s=1$ to $N_{s}, i=0$ to $N_{i}, l=1$ to $N_{l}$

Thermal energy store (TES) operating limits are set according to (5). As shown, the limits of the energy state of the TES are defined by the temperature limits of the TES, the thermal capacitance of the TES and the temperature of the TES environment (which may be the building temperature if the TES is situated inside a building, or may be the outside temperature if the TES stands alone).

$$
\begin{aligned}
\left(X_{l}^{\text {min }}-T_{s, i, l}^{T E S e n v}\right) & C x_{l} \leq X_{s, i, l} \\
& \leq\left(X_{l}^{\text {max }}-T_{s, i, l}^{T E S e n v}\right) C x_{l}
\end{aligned}
$$

For all $s=1$ to $N_{s}, i=0$ to $N_{i}, l=1$ to $N_{l}$

\section{2) Initialisation}

To ensure that the produced results are not distorted, the value of any energy stored within a TES at the initial timestep must be set as equal to the last time-step (6).

$$
X_{s, 0, l}=X_{s, N_{i}, l}
$$

For all $s=1$ to $N_{s}, l=1$ to $N_{l}$

3) TES system equations

For each TES, the heat from various generator types is aggregated into a TES heat input variable (7). This heat input, along with the heat loss to the environment, the delivered heat, and the state of the TES at the current time-step, determines the TES state at the next time-step (8). The TES heat output variable is the sum of the required space heat and domestic hot water demands (9).

$$
\begin{aligned}
& H_{s, i, 1}^{G B}+H_{s, i, 1}^{C H P}+H_{s, i, l}^{E H P}+H_{s, i, 1}^{E B}=H_{s, i, l}^{i n} \\
& X_{s, i+1, l}=X_{s, i, l}+H_{s, i, l}^{i n}-\frac{\left(\frac{x_{S, i, l}}{C x_{l}}-T_{s, i}^{T E S e n v}\right) t}{R x_{l}}-H_{s, i, l}^{\text {out }} \\
& H_{s, i, l}^{\text {out }}=L_{s, i, l}^{S H}+L_{s, i, l}^{D H W}
\end{aligned}
$$

For all $s=1$ to $N_{s}, i=0$ to $N_{i}, l=1$ to $N_{l}$

\section{B. Reserve modelling}

A critical part of the problem formulation is the constraint set which define the volume of reserve. Reserve is derived from headroom/footroom, in flexible electricity consuming/ generating devices, as appropriate. Below, the right-hand-side of constraint (10) is comprised of the electrical power of electricity consuming flexible devices (i.e., EHP and electric boiler - EB) and the spare capacity in electricity generating devices (i.e., CHP). The sum of these values of footroom and headroom define the total down consumption reserve available.

Constraint (11) is the equivalent constraint for up consumption reserve, with the total up consumption reserve comprising of spare capacity in the flexible electricity consuming devices (i.e., EHP and EB), the delivered power of the flexible electricity generating devices (i.e., CHP).

$$
\begin{aligned}
& R_{i, l}^{r e s d} \leq\left(\frac{H_{s, i, l}^{E H P}}{t \rho_{s, i, l}^{E H P}}-P(e)_{l}^{E H P m i n}\right) \\
& +\frac{\left(H_{s, i, l}^{E B} / t-P(t)_{l}^{E B \min }\right)}{\rho_{l}^{E B}} \\
& +\frac{\left(P(t)_{l}^{C H P \max }-H_{s, i, l}^{C H P} / t\right) \eta_{l}^{e}}{\eta_{l}^{t}} \\
& R_{i, l}^{r e s u} \leq\left(P(e)_{l}^{E H P \max }-\frac{H_{s, i, l}^{E H P}}{t \rho_{s, i, l}^{E H P}}\right) \\
& +\frac{\left(P(t)_{l}^{E B \max }-H_{s, i, l}^{E B} / t\right)}{\rho_{l}^{E B}} \\
& +\frac{\left(H_{s, i, l}^{C H P} / t-P(t)_{l}^{C H P \min }\right) \eta_{l}^{e}}{\eta_{l}^{t}} \\
& R_{i, l}^{\text {resd }}, R_{i, l}^{\text {resu }} \geq 0
\end{aligned}
$$

For all $s=1$ to $N_{s}, i=0$ to $N_{i}, l=1$ to $N_{l}$

Constraints (10)-(12) define the reserve at each location, for every time step. Constraints (13) and (14) aggregate these values into VPP values, using the VPP-GCP, and GCPlocation maps $\left(\Phi^{V G}\right.$ and $\left.\Phi^{G L}\right)$. The definition of VPP level 
reserve means that there is one value per VPP, which implies that each VPP must provide the same amount of reserve across all time-steps. The formulation also allows for the amount of reserve from each location can vary through the day, giving flexibility to the VPP on how it allocates reserve amongst locations.

$$
\begin{aligned}
& R_{v}^{r e s v d}=\sum_{g=1}^{N_{g}} \Phi_{v, g}^{V G} \sum_{l=1}^{N_{l}} \Phi_{g, l}^{G L} R_{i, l}^{r e s d} \\
& R_{v}^{r e s v u}=\sum_{g=1}^{N_{g}} \Phi_{v, g}^{V G} \sum_{l=1}^{N_{l}} \Phi_{g, l}^{G L} R_{i, l}^{r e s u}
\end{aligned}
$$

For all $i=0$ to $N_{i}, v=1$ to $N_{v}$

\section{Energy balances}

\section{1) Resource-location energy balance}

Energy consumption and generation from specific resources at a location should be aggregated together, to enable price components related to consumption at the location level to be applied. Relations (15) and (16) ensure that a location does not import and export at the same time, whilst (17) and (18) sum up electricity consumption/generation and gas consumption at each location, respectively. Electricity consumption/generation is comprised of EHP and EB consumption, CHP generation, base electricity consumption, and solar/wind generation. The GCP gas balance comprises of CHP and gas boiler gas consumption.

$$
\begin{aligned}
& E(l)_{s, i, l}^{-} \leq M y_{s, i, l} \\
& E(l)_{s, i, l}^{+} \leq M\left(1-y_{s, i, l}\right) \\
& E(l)_{s, i, l}^{-}-E(l)_{s, i, l}^{+}=\frac{H_{s, i, l}^{E P}}{\rho_{s, i, l}^{E H P}}+\frac{H_{s, i, l}^{E B}}{\rho_{s, i, l}^{E B}}-\frac{H_{s, i, l}^{C H} \eta_{l}^{e}}{\eta_{l}^{t}}+ \\
& E_{s, i, l}^{l o a d}-E_{s, i, l}^{\text {solar }}-E_{s, i, l}^{\text {wind }} \\
& G(l)_{s, i, l}^{-}=\frac{H_{s, i, l}^{C H P}}{\eta_{l}^{t}}+\frac{H_{s, i, l}^{G B}}{\eta_{l}^{G B}} \\
& E(l)_{s, i, l}^{-}, E(l)_{s, i, l}^{+}, G(l)_{s, i, l}^{-} \geq 0
\end{aligned}
$$

For all $s=1$ to $N_{s}, i=0$ to $N_{i}, l=1$ to $N_{l}$

\section{2) Location-GCP energy balance}

Energy consumption and generation at the location level should be aggregated at the GCP level, to enable capture of the effect of potential microgrid arrangements (where many locations share one GCP), and so that use-of-system (UoS) charges may be applied. Although this approach does not take into account any distribution network constraints, it is appropriate from a commercial perspective as an aggregator, or similar party, is not bound to consider such constraints, and should only consider, with respect to the network, the charge for which it is liable, which are charged at the GCP level. As dictated by (20) and (21) electricity cannot be imported and exported at the same time. Constraints (22)-(23) calculate the energy balance at the GCP level for electricity and gas respectively.

$$
\begin{aligned}
& \quad E(g)_{s, i, g}^{-} \leq M z_{s, i, g} \\
& E(g)_{s, i, g}^{+} \leq M\left(1-z_{s, i, g}\right) \\
& E(g)_{s, i, g}^{-}-E(g)_{s, i, g}^{+}=\sum_{l=1}^{N_{l}} \Phi_{g, l}^{G L}\left(E(l)_{s, i, l}^{-}-\right. \\
& \left.E(l)_{s, i, l}^{+}\right) \\
& G(g)_{s, i, g}^{-}=\sum_{l=1}^{N_{l}} \Phi_{g, l}^{G L} G(l)_{s, i, l}^{-} \\
& E(g)_{s, i, g}^{-}, E(g)_{s, i, g}^{+}, G(g)_{s, i, g}^{-} \geq 0 \\
& \text { For all } s=1 \text { to } N_{s}, i=0 \text { to } N_{i}, g=1 \text { to } N_{g} \\
& \text { 3) GCP-VPP energy balance }
\end{aligned}
$$

\section{3) GCP-VPP energy balance}

Energy consumption and generation at the GCP level must be aggregated at the VPP level. Equation (25) equates the electricity from the DA market and the imbalance settlement process (ISP), to the relevant GCP level electricity import/export. Equation (26) aggregates GCP level gas imports to the VPP level.

$$
\begin{aligned}
& \quad M_{i, v}+I_{s, i, v}^{-}-I_{s, i, v}^{+}=\sum_{g=1}^{N_{g}} \Phi_{v, g}^{V G}\left(E(g)_{s, i, g}^{-}-\right. \\
& \left.E(g)_{s, i, g}^{+}\right) \\
& \quad G(v)_{s, i, v}^{-}=\sum_{g=1}^{N_{g}} \Phi_{v, g}^{V G} G_{(g) s, i, g}^{-} \\
& I_{s, i, v}^{-} I_{s, i, v}^{+}, G(v)_{s, i, v}^{-} \geq 0 \\
& \text { For all } s=1 \text { to } N_{s}, i=0 \text { to } N_{i}, v=1 \text { to } N_{v}
\end{aligned}
$$

\section{Objective}

As shown in (28), the various relevant costs are distinguished by the level at which they are applied. VPP level prices include the DA market price $\left(\lambda_{i}\right)$ (assumed to be known in the first stage), gas energy price $\left(\gamma_{i}\right)$ and reserve availability prices $\left(\pi_{i}^{d}, \pi_{i}^{u}\right)$, and the uncertain ISP electricity prices $\left(\mu_{s, i}^{-}\right.$, $\left.\mu_{s, i}^{+}\right)$. At the GCP level various UoS charges are combined into one price, for electricity $\left(\chi(g)_{s, i, g}^{-}\right)$and gas $\left(\varepsilon(g)_{s, i, g}^{-}\right)$. Given that UoS fees can be uncertain, these vary by scenario. At the location level, various tax charges are applied, to electricity consumption $\left(\chi(l)_{l}^{-}\right)$and gas consumption $\left(\varepsilon(l)_{l}^{-}\right)$. Also at the location level are incentive payments for CHP, solar photo-voltaic, wind turbine electricity generation $\left(\varkappa_{l}^{C H P}\right.$, $\varkappa_{l}^{P V}, \varkappa_{l}^{W T}$ respectively), and for EHP heat generation $\left(\varkappa_{l}^{E H P}\right)$.

$$
\begin{aligned}
& \operatorname{Min}\left\{\sum _ { s = 1 } ^ { N _ { s } } \left[p _ { s } \sum _ { i = 1 } ^ { N _ { i } } \left(\sum _ { v = 1 } ^ { N _ { v } } \left(\lambda_{i} M_{i, v}+\mu_{s, i}^{-} I_{s, i, v}^{-}-\right.\right.\right.\right. \\
& \left.\mu_{s, i}^{+} I_{s, i, v}^{+}+\gamma_{i} G(v)_{s, i, v}^{-}-\pi_{i}^{d} R_{v}^{r e s v d} t-R_{v}^{r e s v u} t\right)+ \\
& \sum_{g=1}^{N_{g}}\left(\chi(g)_{s, i, g}^{-} E(g)_{s, i, g}^{-}+\varepsilon(g)_{s, i, g}^{-} G(g)_{s, i, g}^{-}\right)+ \\
& \sum_{l=1}^{N_{l}}\left(\chi(l)_{l}^{-} E(l)_{s, i, l}^{-}+\varepsilon(l)_{l}^{-} G(l)_{s, i, l}^{-}+\right. \\
& \frac{\mathcal{x}_{l}^{C H P} \eta_{l}^{t} H_{s, i, l}^{C H P}}{\eta_{l}^{e}}+\mathcal{X}_{l}^{P V} E_{s, i, l}^{\text {solar }}+\varkappa_{l}^{W T} E_{s, i, l}^{\text {wind }}+ \\
& \left.\left.\left.\left.\mathcal{X}_{l}^{E H P} H_{s, i, l}^{E H P}\right)\right)\right]\right\}
\end{aligned}
$$

\section{CASE STUDY DESCRIPTION}

The described model is demonstrated through application to a district of mixed residential and commercial buildings in the Republic of Ireland. The model operates at the DA stage and wholesale markets are assumed to operate DA. The district acts as a VPP (to access power system markets, such as for operating reserve $-\mathrm{OR}$ ), and is thus balancing responsible, and hence liable for imbalances. Below, the district, in particular the energy generation and storage devices and demand profiles, are described. Subsequently, the BCs studied, and the prices from the relevant markets and charging regimes are described. Estimates of annual operational revenue results are made by running the described model for seven days (covering the different seasons and weekdays/weekends), as described in [17]. The model is run with nine scenarios, to capture uncertainty in ISP prices and demand/renewable generation. First stage decisions are the DA and reserve market activity, whilst heat generation, TES set points, ISP activity and location/GCP level energy 
import/export are recourse decisions. ISP price scenarios are formulated using historical data and a scenario reduction algorithm, as described in [16]. Demand and generation scenarios are formed by randomly perturbing modelled profiles, as described in Section III.A. The number of scenarios chosen is illustrative. To ascertain the required number of scenarios to obtain optimal results, further analysis is required. Each day, for each case, runs in 5-15 minutes in the FICO Xpress program [18], on a Windows-based system with a 3.6-GHz quad core processor and $32 \mathrm{~GB}$ of RAM.

\section{A. District}

The district consists of an office building, leisure center and a block of flats. The buildings are independently managed and connected to the public electricity and gas distribution networks. With reference to the problem formulation, each building is its own VPP, and has its own GCP, in the base case. The energy generation (including wind turbine - WT) and TES of the district are detailed in Table I.

TABLE I: DISTRICT ENERGY RESOURCE CHARACTERISTICS

\begin{tabular}{|l|l|l|l|l|}
\hline Resource & & $\begin{array}{l}\text { Office } \\
\text { block }\end{array}$ & $\begin{array}{l}\text { Leisure } \\
\text { center }\end{array}$ & $\begin{array}{l}\text { Flats } \\
\text { block }\end{array}$ \\
\hline TES & Capacity (liters) & 10500 & 1000 & \\
\hline \multirow{2}{*}{$\begin{array}{l}\text { Gas } \\
\text { boiler }\end{array}$} & Power (kW) & 393 & 900 & \\
\cline { 2 - 5 } & Efficiency & $96 \%$ & $96 \%$ & \\
\hline \multirow{3}{*}{ Gas CHP } & Power (kW) & 82 & 206 & \\
\cline { 2 - 5 } & Electrical efficiency & $34 \%$ & $41 \%$ & \\
\cline { 2 - 5 } & Thermal efficiency & $56 \%$ & $58 \%$ & \\
\hline \multirow{2}{*}{ EB } & Power (kW) & & & 1385 \\
\cline { 2 - 5 } & Efficiency & & & $90 \%$ \\
\hline WT & Rated power (kW) & 10 & & \\
\hline
\end{tabular}

For each building, space heating, domestic hot water, base electricity and wind profiles are taken from historical data. Uncertainty in the profiles is synthesized by randomly varying the given profiles within a set band $(+/-10 \%)$ of the given profile. Previous work has indicated that this variation is realistic [19]. An example of this process is shown in Figure 1Error! Reference source not found., which shows the utilized space heating profiles for the winter weekday season.

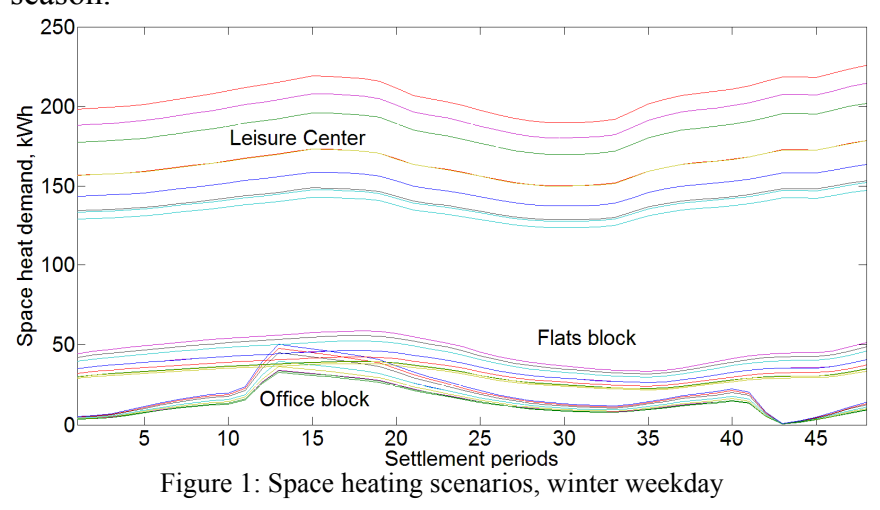

\section{B. Description of case studies}

To demonstrate the potential value of smart energy districts, a number of (energy and capacity) business cases are explored.
The retail optimization (RO) BC demonstrates the value of optimizing each building with respect to static retail prices. The DA, day-ahead \& imbalance (DA\&I), OR, capacity payment (CP) and EDUoS BCs demonstrate the value of optimizing each building with respect to price signals from the various markets and charging regimes. The 'All' BC then shows the value of all price signals. Subsequently, the district coordination (DC) BC shows the value of virtual aggregation, while the district private wire (DPW) BC shows the value of physical aggregation, both optimizing on all price signals.

C. Prices

For the RO BC, retail energy prices (excluding retailer margins and costs) are taken from average Republic of Ireland prices. Electricity import is set at $€ 0.116 / \mathrm{kWh}$, electricity export at $€ 0.0241 / \mathrm{kWh}$, and gas import at $€ 0.0443 / \mathrm{kWh}$. For the optimization, the prices are spread across location, GCP and VPP price elements.

The various price signals for subsequent cases vary by season and time of day. In the Irish system electricity import prices (excluding retailer margin and costs) are made up of multiple elements. At the VPP level wholesale (DA) energy, ISP energy components are relevant for both import and export. $\mathrm{CP}$, which are paid to the system operator and passed to generators, are also relevant at the VPP level. Electricity distribution, transmission and balancing services use-ofsystem (EDUoS, ETUoS and BSUoS) are charged at the GCP level. Value-added-tax (VAT) is charged at the location level. Electricity export prices consist of only wholesale (DA) and ISP prices, as UoS charges, and VAT is not relevant to electricity export. Gas import prices consist of gas energy prices (at the VPP level), gas transmission and distribution UoS fees (at the GCP level), VAT and a gas carbon tax (at the location level).

To demonstrate how prices can vary, Figure 2 shows the variation of the various components of the electricity price through the day, for a selected day. Note that the ISP price components reflect the expected price, as this element is uncertain. The solid lines represent the total DA price for import/export, whilst the dashed lines represent the total realtime price.

\section{RESULTS}

\section{A. Retail price optimization}

Figure 3 shows the impact, on annual cash flows, by price component, of optimization on retail prices, on a load following base. The potential savings from the RO case are $€ 82,800$ /year (17\% saving; from a base of $€ 509,100$ /year, in the load following case). Savings can be attributed to the shifting of electricity consumption and generation to maximize self-consumption of generated electricity at the various buildings (thus minimizing import of electricity, with the associated UoS and tax costs). Electricity wholesale and capacity costs are reduced as the incentive to maximize selfconsumption has a disproportionate impact at times of high energy demand (as there are more electricity imports in the base), which are correlated with times of high energy/capacity price. 

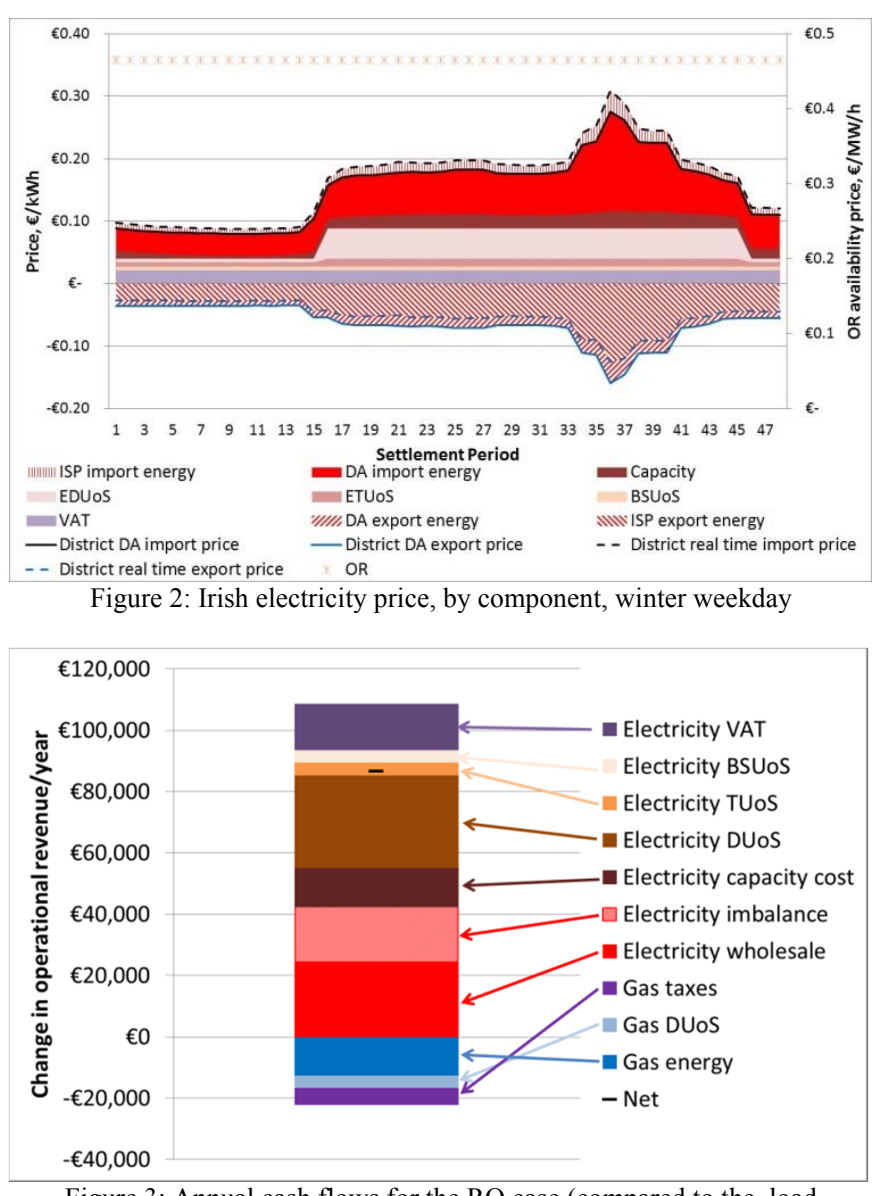

Figure 3: Annual cash flows for the RO case (compared to the load following base)

\section{B. Dynamic price signal optimization}

Figure 4 shows the change in annual cash flows from optimization on various price signals, on the RO base case.

The DA case results in an increase of operational revenue of $€ 11,000 /$ year (2.3\% saving, on the RO case). This is due to two factors. Firstly, the shift in electricity import away from times of high price, to lower price periods (the 'peaky' nature of winter Irish wholesale electricity prices makes time-shifts of even an hour or two profitable during winter periods). Secondly, there is an increase in CHP operation when economic (at times of high electricity price), which also results in reduced electricity VAT costs, but also means increased expenditure on gas, and associated UoS fees and taxes. Compared to the DA case, the DA\&I case increases revenue by an additional $€ 700$ /year $(2.5 \%$ saving on the RO case, in sum). This is due to the shift in electricity market activity away from times of largest difference between DA and ISP prices, which are also the periods of high DA electricity price, see Figure 2. This results in reduced gas CHP operation (which was motivated to operate at times of high DA price, in the DA case), resulting in reduced gas consumption, hence gas-related costs. The OR case produces revenue of $€ 1,300 /$ year ( $0.4 \%$ saving, on the RO case). The value of this $\mathrm{BC}$ is fundamentally limited by the low value of the OR product, though the requirement that the reserve capacity be consistent across the modelled day (which requires a minimum sum of headroom/footroom from electricity generating/consuming devices, which can be maintained throughout the day) also restricts value. The CP case produces an increase in operational revenue of $€ 8,200 /$ year ( $1.9 \%$ saving, on the RO case). Here, revenue is achieved by reducing electricity consumption at the VPP level (on which capacity payments are charged) by increasing CHP electricity generation, and shifting consumption to times of lower capacity charge. The EDUoS case produces an increase in operational revenue of $€ 8,000 /$ year ( $1.7 \%$ saving, on the RO case). This is due to the shift of electricity consumption away from the $8 \mathrm{am}-10 \mathrm{pm}$ period, when EDUoS are highest (see Figure 2). This results in reduced expenditure on electricity-related costs and increased expenditure on gasrelated costs, as this encourages increased CHP operation. Consideration of all price signals results in an increase in operational revenue (on the RO case) of $€ 15,400 /$ year ( $3.7 \%$ saving, on the RO case). Most of these benefits derive form the electricity wholesale market price signals, with some additional benefit derived from the $\mathrm{CP}$ and EDUoS price signals, which largely complement and accentuate the signals from the electricity wholesale market.

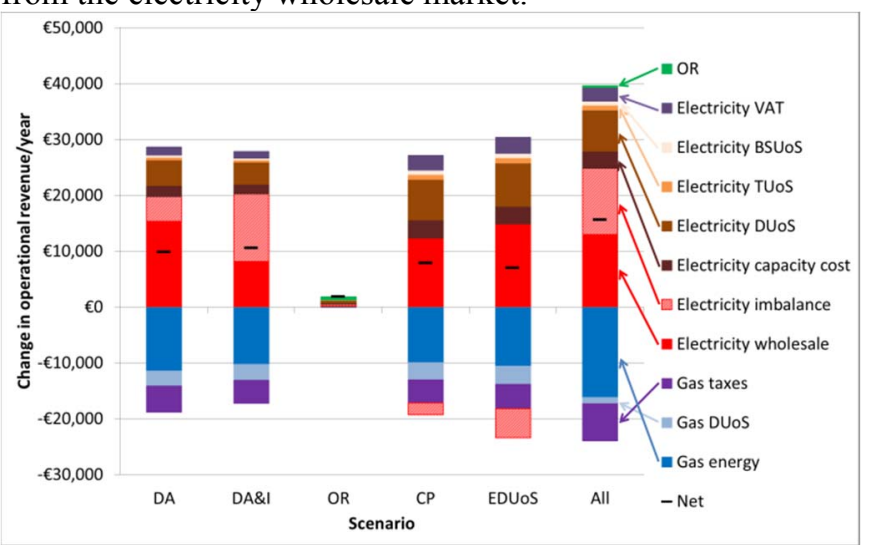

Figure 4: Annual cash flows for various cases (compared to the RO base)

\section{Effect of aggregation}

Figure 5 shows the change in annual cash flows from aggregation (optimizing on all price signals), on the 'All' case. The DC case results in additional revenue of $€ 3,800 /$ year (1\% saving, on the All case). Mostly, this revenue comes from reduced capacity costs, as electricity generation and consumption is coordinated across buildings to reduce the overall district electricity imports. Some revenue from reduced capacity cost is offset by increased gasrelated cost, as CHP operation is increased. The DPW case results in additional revenue of $€ 15,100 /$ year (3.7\% saving, on the All case). Significant revenue is obtained from reduction in electricity UoS costs, as the private-wire arrangement means that it is the net district consumption on which UoS fees are charged, rather than being charged separately on individual buildings. 


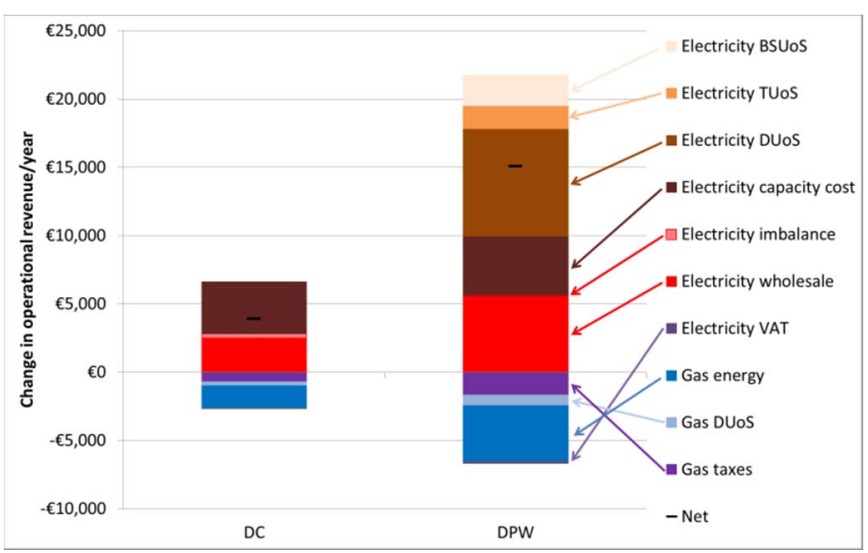

Figure 5: Annual cash flows for aggregation cases (compared to 'All' base)

\section{CONCLUSION}

This paper has presented a stochastic mixed integer linear programming energy/capacity district co-optimization model. Particular features of note are: the general approach (without focus on particular technologies); the incorporation of the capacity, in particular the ability of reserve availability to vary by time step and location (while maintaining the same total availability across the day); and the level of aggregation (commercial/VPP, GCP and location) approach, which enables modelling of virtual and physical aggregation.

The applicability of the presented model was then demonstrated by application of a case study, consisting of a mixed-use district in the Republic of Ireland. Several BCs were assessed. Substantial gains were demonstrated through optimization with respect to retail prices, from using thermal storage and the flexible gas CHP to minimize electricity grid consumption (thus avoiding UoS and tax costs). Further gains were then demonstrated from optimization with respect to several energy and reserve price signals. Utilizing the ability of the model to vary the level of aggregation, gains were demonstrated from district coordination, and installation of a district private wire network (virtual and physical aggregation, respectively).

Use of the proposed approach will help unlock flexibility in smart districts, particularly from multi-energy resources. Further work aims at extending the district model to include building thermal dynamics (hence thermal energy storage in building fabric) and electric vehicles, extension to incorporate heat networks within the district, and possibly to cover multiple market stages. More valuable capacity-related markets, such as for avoidance of distribution network expansion [20], or capacity markets, may also be considered.

\section{ACKNOWLEDGMENTS}

This work was developed with the contribution and within the scope of the FP7 DIMMER project (ref no. 609084) supported by the European Commission, which the authors would like to acknowledge.

\section{REFERENCES}

[1] V. C. Güngör, D. Sahin, T. Kocak, S. Ergüt, C. Buccella, C. Cecati, and G. P. Hancke, "Smart Grid Technologies: Communication Technologies and Standards," IEEE Trans. Ind. Informatics, vol. 7, no. 4, pp. 529-539, Nov. 2011.

[2] S. Althaher, P. Mancarella, and J. Mutale, "Automated Demand Response From Home Energy Management System Under Dynamic Pricing and Power and Comfort Constraints," IEEE Trans. Smart Grid, vol. 6, no. 4, pp. 1874-1883, Jul. 2015.

[3] J. Torriti, M. G. Hassan, and M. Leach, "Demand response experience in Europe: Policies, programmes and implementation," Energy, vol. 35, no. 4, pp. 1575-1583, Apr. 2010.

[4] G. Strbac, D. Pudjianto, P. Djapic, and S. Gammons, "Understanding the Balancing Challenge," 2012.

[5] P. Mancarella and G. Chicco, "Real-Time Demand Response From Energy Shifting in Distributed Multi-Generation," IEEE Trans. Smart Grid, vol. 4, no. 4, pp. 1928-1938, Dec. 2013.

[6] J.-K. Choi, D. Morrison, K. P. Hallinan, and R. J. Brecha, "Economic and environmental impacts of community-based residential building energy efficiency investment," Energy, vol. 78, Elsevier Ltd, pp. 877-886, Dec-2014.

[7] B. Azzopardi, E. A. Martínez-Ceseña, and J. Mutale, "Decision support system for ranking photovoltaic technologies," IET Renew. Power Gener., vol. 7, no. 6, pp. 669-679, Aug. 2013.

[8] E. Merkel, R. McKenna, and W. Fichtner, "Optimisation of the capacity and the dispatch of decentralised micro-CHP systems: A case study for the UK," Appl. Energy, vol. 140, pp. 120-134, Feb. 2015.

[9] C. Schwaegerl, L. Tao, P. Mancarella, and G. Strbac, "A multiobjective optimization approach for assessment of technical, commercial and environmental performance of microgrids," European Transactions on Electrical Power, vol. 21, pp. 12711290, Mar-2011.

[10] A. Ahmed and P. Mancarella, "Strategic techno-economic assessment of heat network options for distributed energy systems in the UK," Energy, vol. 75, pp. 182-193, Oct. 2014.

[11] D. Papadaskalopoulos, G. Strbac, P. Mancarella, M. Aunedi, and V. Stanojevic, "Decentralized Participation of Flexible Demand in Electricity Markets-Part II: Application With Electric Vehicles and Heat Pump Systems," IEEE Trans. Power Syst., vol. 28, no. 4, pp. 3667-3674, Nov. 2013

[12] E. Karangelos and F. Bouffard, "Towards Full Integration of Demand-Side Resources in Joint Forward Energy/Reserve Electricity Markets," IEEE Trans. Power Syst., vol. 27, no. 1, pp. 280-289, Feb. 2012.

[13] M. C. Bozchalui, S. A. Hashmi, H. Hassen, C. A. Cañizares, and K. Bhattacharyya, "Optimal Operation of Residential Energy Hubs in Smart Grids," IEEE Trans. Smart Grid, vol. 3, no. 4, pp. 17551766, 2012.

[14] T. Capuder and P. Mancarella, "Techno-economic and environmental modelling and optimization of flexible distributed multi-generation options," Energy, vol. 71, pp. 516-533, Jul. 2014. N. Neyestani, M. Yazdani-Damavandi, M. Shafie-khah, G. Chicco, and J. P. S. Catalao, "Stochastic Modeling of Multi-Energy Carrier Dependencies in Smart Local Networks with Distributed Energy Resources," IEEE Trans. Smart Grid, vol. 6, no. 4, pp. 1748-1762, Jul. 2015

[16] N. Good, E. Karangelos, A. Navarro-Espinosa, and P. Mancarella, "Optimization under Uncertainty of Thermal Storage-Based Flexible Demand Response with Quantification of Residential Users' Discomfort," IEEE Trans. Smart Grid, vol. 6, no. 5, pp. 2333-2342, Sep. 2015

[17] N. Good, E. A. Martínez-Ceseña, L. Zhang, and P. Mancarella, "Techno-Economic and Business Case Assessment of Low Carbon Technologies in Distributed Multi-Energy Systems," Appl. Energy, vol. In Press, 2015.

[18] "Xpress." FICO, San Jose, CA, USA, 2011.

[19] N. Good, L. Zhang, A. Navarro-Espinosa, and P. Mancarella, "High resolution modelling of multi-energy domestic demand profiles," Appl. Energy, vol. 137, pp. 193-210, Jan. 2015. E. A. Martínez-Ceseña, N. Good, and P. Mancarella, "Electrical network capacity support from demand side response: Technoeconomic assessment of potential business cases for small commercial and residential end-users," Energy Policy, vol. 82, pp. 222-232, Jul. 2015. 